\title{
Case Report \\ Survival after Drowning with Cardiac Arrest and Mild Hypothermia
}

\author{
S. S. Rudolph and S. Barnung \\ Department of Anaesthesia, Centre of Head and Orthopaedics, Copenhagen University Hospital, Rigshospitalet, \\ Blegdamsvej 9, 2100 Copenhagen, Denmark
}

Correspondence should be addressed to S. S. Rudolph,rudolph@dadlnet.dk

Received 24 February 2011; Accepted 7 April 2011

Academic Editors: T. Noda and P. E. Puddu

Copyright (C) 2011 S. S. Rudolph and S. Barnung. This is an open access article distributed under the Creative Commons Attribution License, which permits unrestricted use, distribution, and reproduction in any medium, provided the original work is properly cited.

\begin{abstract}
The current guidelines for resucitation following hypothermia and submersion with cardiac arrest state that rewarming should be continued until a core temperature of $32-34^{\circ} \mathrm{C}$ is achieved, after which death can be declared if no return of spontaneous circulation has occurred. As no randomized, controlled trials exist, these treatment guidelines are mostly based on a pragmatic approach. Wheater to start or stop resuscitation is notoriusly difficult. Submersion time, water temperature, and prompt resuscitation seem to be crucial factors for outcome. We report a case of successful resuscitation after the use of mechanical chest compressions and extracorporeal circulation in a patient with cardiac arrest due to submersion and accompanying mild hypothermia with a core temperature of $32,2^{\circ} \mathrm{C}$ caused by submersion.
\end{abstract}

\section{Introduction}

Submersion with cardiac arrest is a great challenge. Submersion time, water temperature, and prompt resuscitation seem to be crucial factors for outcome. Submersion in icy water $\left(<5^{\circ} \mathrm{C}\right)$ may provide protection against cerebral hypoxia. Case reports have shown that survival with good neurologic outcome is possible. As no randomized, controlled trials exist, treatment guidelines are mostly based on a pragmatic approach. The current guidelines state that rewarming should be continued until a core temperature of $32-34^{\circ} \mathrm{C}$ is achieved [1], after which death can be declared if no return of spontaneous circulation has occurred.

We report a case of successful resuscitation after the use of mechanical chest compressions and extracorporeal circulation in a patient with cardiac arrest due to submersion and accompanying mild hypothermia with a core temperature of $32,2^{\circ} \mathrm{C}$ caused by submersion.

\section{The Case}

45-year-old male was winter swimming in icy water. When trying to swim from one hole in the ice to another he got disoriented and was caught under the ice. He was brought up by rescuedivers after approximately 20 minutes. He was pulseless with an initial rhythm of asystole. Endotracheal intubation was performed on the site, and he was transported to hospital with ongoing manual chest compressions and ventilation. Epinephrine $4 \mathrm{mg}$ and atropine $3 \mathrm{mg}$ was administered en route to the hospital. End-tidal carbon dioxide $\left(\mathrm{EtCO}_{2}\right)$ was between 1.6 and $6 \mathrm{kPa}$. Upon arrival at the emergency department (ED), approximately 70 minutes after the accident, he was still in cardiac arrest with asystole, and mechanical chest compressions were started (LUCAS, Jolife AB, Lund, Sweden). EtCO 2 was 3,0 kPa. Initial bladder temperature was $32,2^{\circ} \mathrm{C}$. He had a profound combined metabolic and respiratory acidosis with a $\mathrm{pH}$ of 6.47 , Spotassium was $3,9 \mathrm{mMol} / \mathrm{L}$. Mechanical chest-compressions were continued until extracorporeal circulation (ECC) was established approximately $110 \mathrm{~min}$ after the accident. Approximately 190 min after the accident a central temperature of $34^{\circ} \mathrm{C}$ was reached; spontaneous cardiac activity was established initially as nodal rythme and then sinus rythme. Further rewarming was withheld. A bronchoscopy preformed during ECC showed signs of pulmonary edema. ECC was discontinued and he was transferred to the intensive 
care unit where he received further fluid resuscitation and inotropic support. Mild hypothermia was continued for 24 hours after which he was rewarmed to normothermia. He remained stable and was gradually weaned from mechanical ventilation.

Early during rewarming universal myoclonus was observed and treatment with levetiracetam (Keppra) was initiated. After sedation was discontinued he initially remained in a stuporous-like state of consciousness, but gradually the myoclonus decreased and he regained consciousness. Initial signs of anoxic brain damage on electroencephalography (EEG) and computed tomography (CT) of the cerebrum also regressed on repeated EEG and CT.

On day 21 after the accident he was conscious and responded coherently to questions but some disorientation and myoclonus persisted. He was transferred to a neurorehabilitation unit where he is currently making progress.

\section{Discussion}

The treatment of cardiac arrest due to cold submersion and cardiac arrest is difficult. The questions are whether the patient suffered a cardiac arrest as a consequence of hypothermia and then drowned or did hypothermia occur after drowning. Even though a hypothermia victim may appear dead, resuscitation and good neurologic outcome is possible, although unusual. A general assumption is "no one is dead until warm and dead". But how "warm" is warm? In the current guidelines a core temperature of $32-34^{\circ} \mathrm{C}$ is suggested.

It is generally accepted that an S-potassium $>10 \mathrm{mMol} / \mathrm{L}$ ( $>12$ in children) is a predictor of death [2] in patients suffering accidental hypothermia. Likewise a sustained low $\mathrm{EtCO}_{2}<2 \mathrm{kPa}$ in the face of good quality chest compressions is considered a maker of poor outcome in cardiac arrest.

In the current case, the patient presented to the ED with asystole, a $\mathrm{pH}$ of 6.47 , and a core temperature of $32,2^{\circ} \mathrm{C}$ with ongoing advanced cardiac life support for more than 50 minutes. Under normal conditions, cessation of resuscitation efforts would be considered. The decision to initiate rewarming by ECC even though the patient was above the lower temperature threshold presented in the guidelines was based on a clinical judgement. Furthermore an acceptable circulation had been maintained during transport as evidence by an $\mathrm{EtCO}_{2}$ between 1,6 and $6 \mathrm{kPa}$, and the $\mathrm{S}$ potassium was $3,9 \mathrm{mmol} / \mathrm{L}$.

Survival from cardiac arrest depends on the chain of survival and if any link is inadequate, survival rates will diminish. In the current case good quality basic life support with manual chest compressions was established after initial rescue. Oxygenation and ventilation via endotracheal intubation were maintained and transport to an appropriate facility was provided. In case of accidental hypothermia and cardiac arrest, transport to a facility with EEC capablity is crucial, since ECC probably provides the best means of rewarming in this situation [3]. This should be considered even in the face of longer transportation. Good quality chest compressions, either manually or mechanically, must be maintained, during transport and no rewarming should be provided before ECC.

In the current case the patient was marginally "too warm" according to current guidelines $[1,4]$, and further resuscitation efforts could have been considered futile. We chose to proceed till rewarming by ECC based on clinical judgement and on the fact that adequate cardiopulmonary resuscitation had been provided. Temperature measurements are inherently imprecise and may not reflect core temperature $[5,6]$, which should be remembered when caring for the hypothermic patient.

\section{References}

[1] C. D. Deakin, L. J. Morrison, P. T. Morley et al., "Advanced life support: 2010 International Consensus on Cardiopulmonary Resuscitation and Emergency Cardiovascular Care Science with Treatment Recommendations," Resuscitation, vol. 81, supplement 1, pp. e93-e174, 2010.

[2] P. R. Bender, D. J. Debehnke, G. L. Swart, and K. N. Hall, "Serum potassium concentration as a predictor of resuscitation outcome in hypothermic cardiac arrest," Wilderness and Environmental Medicine, vol. 6, no. 3, pp. 273-282, 1995.

[3] R. R. Kempainen and D. D. Brunette, "The evaluation and management of accidental hypothermia," Respiratory Care, vol. 49, no. 2, pp. 192-205, 2004.

[4] B. Kjærgaard, S. F. Rudolph, A. Lucas, and H. O. Holdgaard, "Treatment of the hypothermic patient," Ugeskrift for Laeger, vol. 170, no. 23, pp. 2005-2010, 2008.

[5] S. F. Rudolph, T. Mantoni, and B. Belhage, "Pathophysiology in accidental hypothermiaPatofysiologi ved accidentel hypotermi," Ugeskrift for Laeger, vol. 169, no. 45, pp. 3845-3849, 2007.

[6] A. Mulcahy and M. Watts, "Accidental hypothermia: an evidence-based approach," Emergency Medicine Practice, vol. 11, no. $1,2009$. 


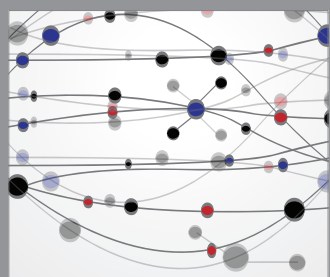

The Scientific World Journal
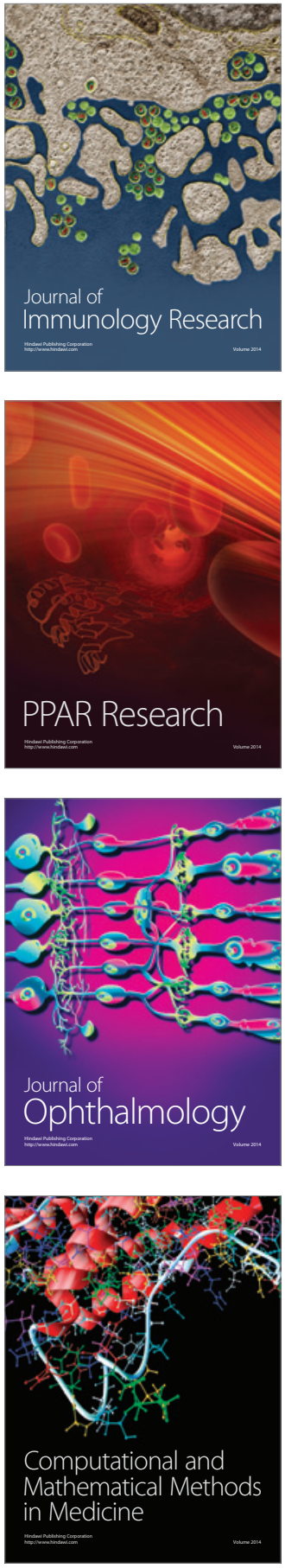

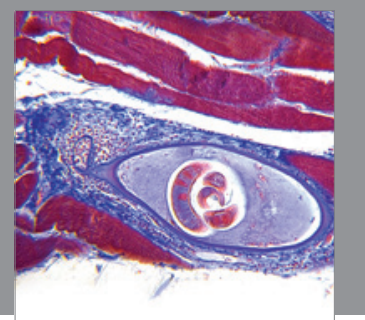

Gastroenterology

Research and Practice
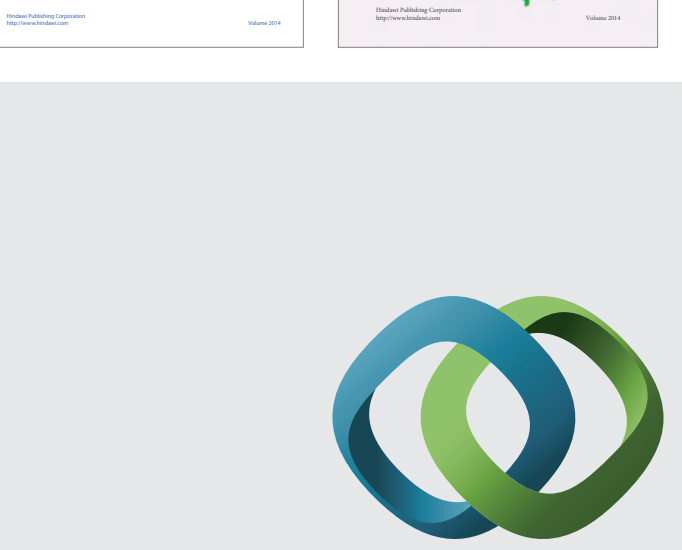

\section{Hindawi}

Submit your manuscripts at

http://www.hindawi.com
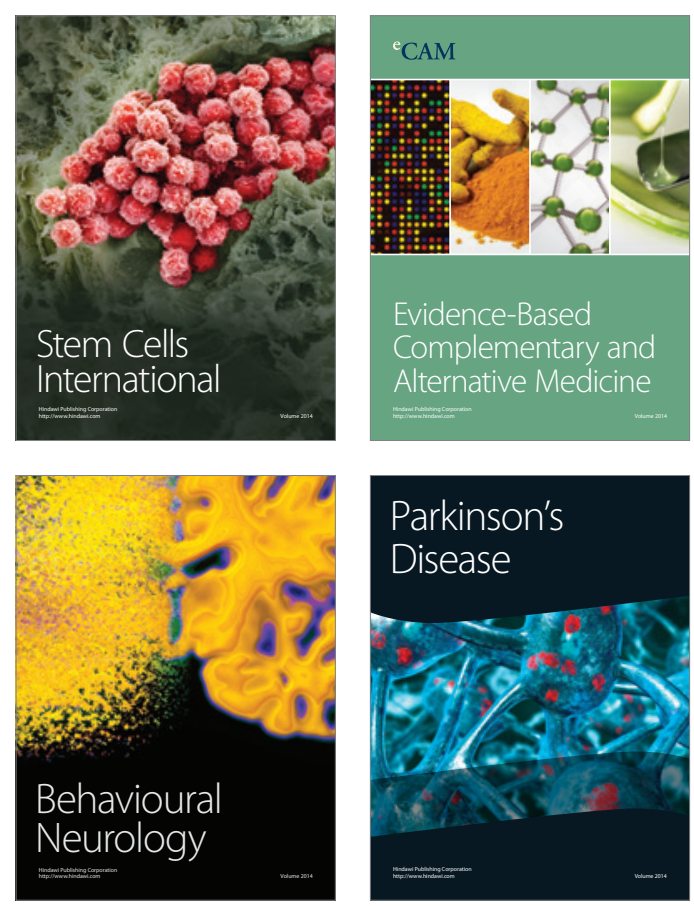

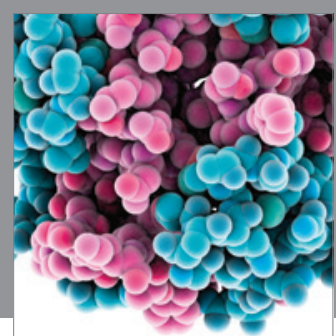

Journal of
Diabetes Research

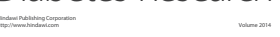

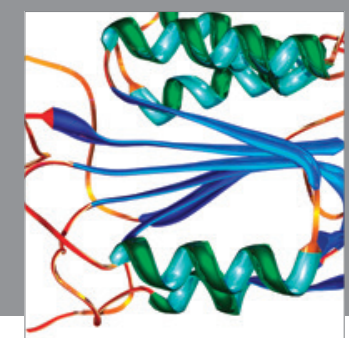

Disease Markers
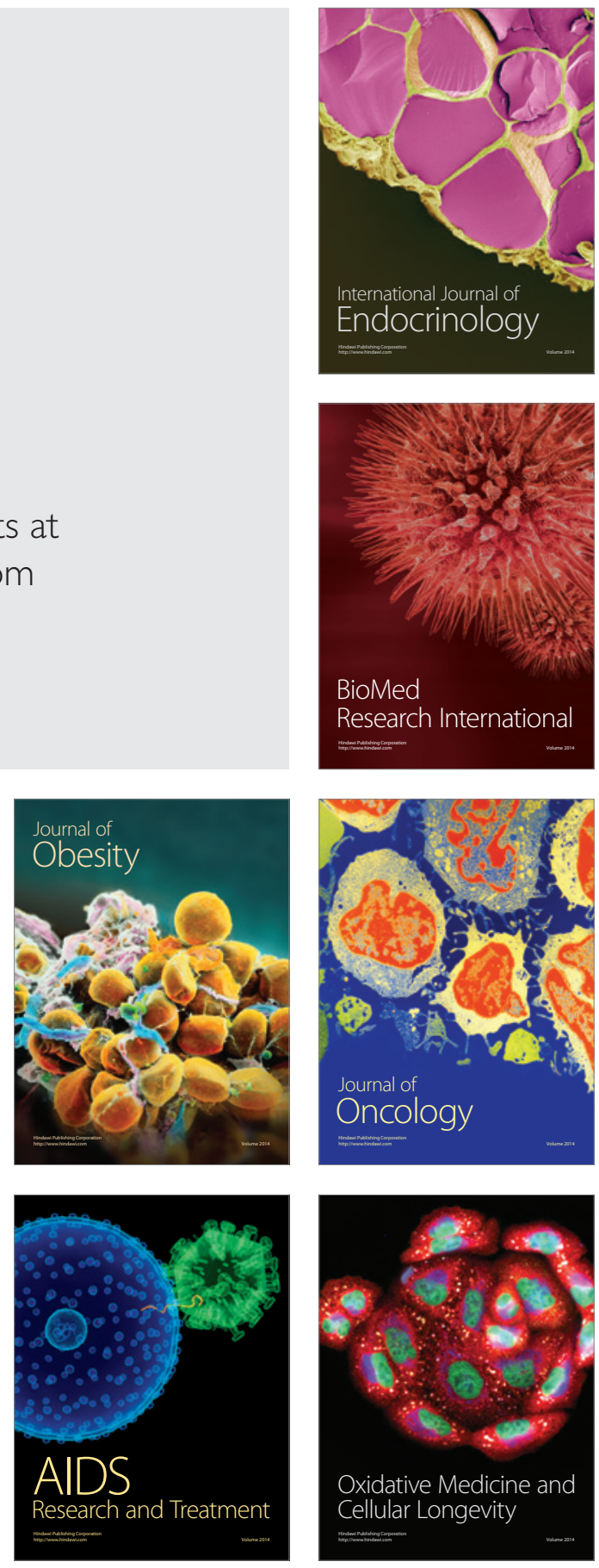